\title{
PERSPECTIVES OF CANADIAN DISTANCE EDUCATORS ON THE MOVE TO ONLINE LEARNING
}

\author{
CINDY IVES \\ ATHABASCA UNIVERSITY
}

\author{
PAMELA WALSH \\ ATHABASCA UNIVERSITY
}

\begin{abstract}
Our qualitative study explored transition in seven Canadian universities-early providers of distance education that transitioned to online learning between 2002 and 2017. We interviewed 16 individuals who were involved in the design, planning, or implementation of online learning. Participants reported their universities experienced significant impacts on organizational structure and roles. Many saw an increased focus on learning and teaching. Access, revenue generation, and technology were identified as drivers of online learning; traditional learning and teaching practices were shifting; challenges experienced included resistance to change and lack of dedicated resources; and effective, visionary leadership was seen to be critically important. We propose that the roots of today's challenges and opportunities in online learning may be found in the experiences of distance educators who were early adopters.
\end{abstract}

Keywords: organizational change, distance education, online learning, Canadian universities

\section{Résumé}

Notre étude qualitative explore la transition dans sept universités canadiennes qui sont passées à l'apprentissage en ligne entre 2002 et 2017 et comptent parmi les premiers fournisseurs d'enseignement à distance. Nous avons interrogé 16 personnes qui ont participé à la conception, à la planification ou à la mise en œuvre de l'apprentissage en ligne. Les participants ont indiqué que leurs universités avaient subi des changements importants en ce qui concerne la structure organisationnelle et les différents rôles. L'accessibilité, la génération de revenus et la technologie ont été désignées comme des facteurs du passage à l'enseignement en ligne; les pratiques traditionnelles d'apprentissage et d'enseignement ont évolué; les défis rencontrés comprennent la résistance au changement et le manque de ressources spécialisées; et un leadership efficace et visionnaire a été mentionné comme un élément crucial. Nous proposons que les racines des défis et des occasions d'aujourd'hui en matière d'apprentissage en ligne se retrouvent dans les expériences des éducateurs à distance qui ont été parmi les premiers à adopter cette approche.

Mots-clés : changement organisationnel, enseignement à distance, apprentissage en ligne, universités canadiennes

\section{Introduction}

The challenges facing higher education in the 21st century are well documented. Higher education is shaped by social, technological, economic, and political trends including demographic changes, calls for greater equality and access by non-traditional students, technological advancements, questions about the future of work and skills, and declining government support (Cameron,
2002; EDUCAUSE, 2020; Organisation for Economic Co-operation and Development, 2019). These challenges and questions have inspired calls for higher education change and reform in Canada and beyond (Brown, 2013; Hughes \& Mighty, 2010). Global participation in higher education has steadily increased in recent decades (United Nations Educational, Scientific and Cultural Organization, 2018); Canada has experienced significant growth during this same period (Statistics 
Canada, 2020). World-wide participation in online learning has also increased (Palvia et al., 2018). With the first learning management systems, educational institutions began to experiment with web-based courses and teaching environments, and online learning was poised to become part of the mainstream of higher education by the beginning of the 21st century (Weller, 2020).

As distance educators, former vice presidents, and change agents with more than 25 years' experience in Canadian higher education, we identified the need for a study to explore the experiences of distance education colleagues across the country as they transitioned their programs into online modalities. This report documents our initial findings.

\section{Distance Education and Online Learning}

Initially in Canada, it was the single-mode (distance education only) and dual-mode universities (place-based with distance education programs, often through a continuing education unit) (Guri-Rosenblit, 2014; Qayyum \& Zawacki-Richter, 2018) that adopted online learning. Distance education, historically defined as a system of teaching and learning where instructors and students are separated in time and/or place (Holmberg, 1994; Keegan, 1993; Peters, 2002), includes five generations of mediation (Anderson, 2008). Correspondence education, characterized by print-based course materials distributed by postal mail, is an example of the first generation. As communication technologies advanced, succeeding generations incorporated two-way interactions through telephone, mass media, teleconferencing, and computer conferencing. Distance education is traditionally designed using a systematic process, supported by instructional designers and technologists who work closely with subject matter experts to ensure that courses and programs are focused on learner needs and the alignment of learning strategies, activities, and assessments with instructional objectives. Various forms of interaction are facilitated (Anderson, 2008; Holmberg, 1994; Keegan, 1993; Peters, 2002). Currently, the internet mediates synchronous and asynchronous communication, and online learning is understood to be a recent form of distance education (Anderson, 2008; Johnson, 2019).

While Canadian reports revealed a growing interest in and attention to online learning (Advisory Committee for Online Learning, 2001; Council of Ministers of Ed- ucation, 2001), there are suggestions that its early potential was not realized (Canadian Council on Learning, 2009; Charpentier et al., 2006). Not until recently were there national studies on the prevalence of online learning in Canada (Donovan \& Bates, 2018; Johnson, 2019).

Researchers have suggested there is a documented lack of good quality systematic research in the field of distance education (Fredericksen, 2017; Guri-Rosenblit, 2014; Paul, 2014) and have recommended that future studies of distance education include a focus on organization and management (Paul, 2014), the critical importance of university culture (Marshall, 2010a), and the role of academic leadership in supporting online learning (Beaudoin, 2016; Fredericksen, 2017). Our study offers some insights into these issues. We examined the experiences of seven Canadian universities that moved to offering online courses and programs between 2002 and 2017. Most participating universities had a history of correspondence-type distance education using print and integrated media. Our study investigated selected academic and administrative changes resulting from the transition. The research objectives were to understand the drivers that influenced the decision to adopt online learning. We explored factors and conditions that led to or inhibited success, academic models that emerged, and lessons learned by these universities. Our findings may provide new perspectives on the social, economic, and educational potential of online learning as promoted in the literatures on leadership of change and the impact of technology, briefly described below.

\section{Organizational Culture and Leadership}

Universities are centuries-old organizations, the culture and characteristics of which require considered approaches and strategies to facilitate successful change (Boyce, 2003; Paul, 2014). Leaders who understand cultural dynamics are better prepared to address organizational challenges and resistance to change (Caruth \& Caruth, 2013). Seeking to understand the relationship between institutional culture and strategies, Kezar and Eckel (2002) affirmed that "change strategies may be successful if they are culturally coherent" (p. 457).

Given the endurance of traditional university models and cultures and the predominance of loosely coupled academic structures, Gioia and Thomas (1996) proposed that organizational sensemaking processes could inspire individuals and groups to collectively reinterpret 
goals and develop new meanings and beliefs. Others elaborated, suggesting that institutionalization of transformational change efforts required engaging in deep sensemaking processes throughout the implementation phases (Kezar, 2013; Weick et al., 2005). While acknowledging the potential for transformative change, some have argued that educational practices have not been altered. (Norris et al., 2013; Salmon \& Angood, 2013).

The importance of leadership in facilitating academic change is well documented (Brown, 2013; Graetz \& Smith, 2010; Marshall, 2010a; Paul, 2015). Higher education leaders can assist others to develop new institutional identities, supporting and motivating them to initiate desired innovations. Whereas traditional leadership theories have often focused on hierarchical individual leaders and their traits and actions (Bass \& Riggio, 2006), complexity leadership theory (CLT) describes leadership as an emergent event that occurs as a result of interactions between individuals and groups generating system-wide changes and innovation (Lichtenstein et al., 2006). CLT provides a framework for leadership that enables the "learning, creative, and adaptive capacity...in knowledge-producing organizations and organizational units" (Uhl-Bien et al., 2007). This leadership paradigm provides space for organizational sensemaking, shares characteristics with distributive or collaborative leadership (Brown, 2013; Gronn, 2000), and acknowledges the role of formal leaders in fostering organizational adaptability (Uhl-Bien \& Arena, 2018). Similarly, Bates and Sangrà (2011) argued that in order to build better colleges and universities, individual leadership is insufficient, enabling interaction among key players is critical, and new visions for teaching and learning are needed.

\section{Organizational Change and Technology}

Gioia and Thomas (1996) suggested that the shift from an environment of predictable funding and enrolments into a competitive marketplace in the 1990s led to calls for universities to adapt by integrating newly available information and communication technologies. In particular, the potential of novel productivity, learning, and course management software inspired distance education thought leaders in Canada and elsewhere (Daniel, 1999; Laurillard, 2002) to urge the adoption of online technologies in teaching and learning environments. Peters argued that "the achievements of information and communication technologies [would require]...the design of new formats of learning and teaching and [would cause] powerful and far-reaching structural changes of the learning-teaching process" (2002, p. 20). Distance education offers the potential to disrupt traditional higher education teaching and learning models through the incorporation of technologies.

Research on barriers to distance education proposed that cultural changes (Chen, 2009) would be needed to fully implement the promise of technology-enhanced, accessible learning. A study that documented pressures for technology adoption and impact on university cultures predicted success factors would be "related to variables such as organisational mission, goals, culture, and practices" (Ives, 2002, p. iii). Simonson et al. (2012) listed barriers including resistance to change and weaknesses in shared vision and strategic planning; King and Boyatt (2015) identified strategic direction as critical to the adoption of e-learning.

Ives proposed "a multiple perspective, collaborative approach....to integrating] technology across the university system in the service of teaching and learning" (2002, p. 176). Marshall's benchmarking study within universities on several continents emphasized that they had not demonstrated the capability to disrupt their academic models and concluded that changes resulting from technology adoption would depend on the change culture and decisions made by leaders (Marshall, 2010b). Norris and colleagues (2013) argued that higher education failed to achieve the systemic change needed for transformation because it had not leveraged technology to change educational practices, rather it had "layered technology" over its educational practices (p. 7). Others lamented the slow adoption of learning technologies, citing the need for effective support services (Nworie, 2006; Russell, 2009). Salmon and Angood (2013) called for integrated and effective partnerships among techno-pedagogical specialists to adopt technology in support of teaching and learning. Scoppio and Covell (2016) reported that a lack of instructor support contributed to the limited use of learning technologies or misalignment of technology with pedagogical approaches. They recommended that pedagogy should be the focus and that, before adoption, technologies should be critically evaluated for pedagogical appropriateness and relevance.

Our review revealed literature describing significant global growth in online learning. Common themes included organizational culture and the complexity of 
change in higher education, the role of leadership, and the potential of distance education and online technologies to impact teaching and learning. While the literature anticipates significant change, there is little evidence of how it can be (or has been) facilitated or managed. We were interested in moving beyond the potential and possibilities to a deeper understanding of the real-life experiences of others and how their insights could provide evidence-based practice and point the way to further research.

\section{Research Questions}

In light of our own transition experiences, our reading of the literature, and world-wide growth of online learning, we conducted a qualitative study of selected Canadian universities offering online distance education programs. Our study investigated academic and administrative changes implemented as a result of the move to online learning. We were interested in the main drivers of change, what changes emerged and whether they have been effective, what lessons have been learned, and what recommendations are offered by those who manage change.

\section{Methodology}

\section{Research Design}

Our study was an emergent qualitative and exploratory research study (Denzin \& Lincoln, 2018). Using a constructivist, interpretive approach we designed an investigation that would build on our experience with distance and online education. The study was small enough in scale to manage a large volume of data, yet was representative enough to provide insights into the potential of online higher education in Canada. We had no expectation of being able to generalize the results, however others may determine how our findings might apply in their contexts (Denzin \& Lincoln, 2018). This section reports on the conduct of interviews, transcription, coding, and descriptive analysis.

\section{Participants}

As a convenience sample, we selected seven universities in six provinces from our knowledge of their history and experience in Canadian distance education; all were members of the Canadian Virtual University (CVU), a national organization that promoted and supported online learning and collegial cross-institutional partnerships. While they included a mix of traditional place-based universities with long histories and more recently established institutions with provincial mandates for alternative delivery including open and online approaches, the common denominator was their commitment to distance education. All seven made substantial progress toward transitioning from traditional, face-to-face, or correspondence education offerings to some level of online delivery between 2002 and 2017. To separate and de-identify the unique experiences of each university, we assigned alphabetic codes, which are used in the sections that follow. All participating universities provided ethical review and institutional permission for our research.

CVU board members helped us identify institutional representatives as candidates for interviews. We chose 16 participants based on their position, responsibilities, knowledge of and experience with distance education, and willingness to join the study; all were involved in the planning, design, and implementation of the move to online learning in their universities, and all returned signed consent forms. The various roles of our interviewees included instructional designer, director, dean, vice provost, and provost, evidence of leadership at multiple levels within these universities.

\section{Researcher-Participant Relationships}

We had both been involved with the board and advisory committee of the CVU. Our positions as higher education leaders with networks of colleagues with similar responsibility across the country had already led to conversations about successes and challenges in the online distance education space, and our prior relationships with those who agreed to contribute may have inspired their participation as our study was aligned with their interests.

Before we started our interviews, we reflected on our lived experiences in Canadian distance education through our executive and management positions and their relationship to our own earlier individual research initiatives in technology integration and leadership. Further acknowledging our positionality (Palaganas et al., 2017) we designed methodological practices that established a rigorous study leading to credible results (Maher et al., 2018). We shared our backgrounds and experiences with our participants as well, allowing for building of trust and trustworthiness. 


\section{Data Collection}

We conducted and transcribed interviews, analyzed the transcripts through coding and summarizing our findings, and collected relevant university documents for later analysis. We used a university-based SharePoint Group and associated support and collaboration technologies to store our data in easily accessible, secure cloud locations.

Together we conducted 15 open-ended interviews with 16 individuals (one interview involved two people, at their request) using Skype, Zoom, or telephone technologies, based on comfort level of participants and availability of stable technology. The interviews averaged two hours. We developed the interview protocol from questions informed by our own experiences as well as by the literature review and our research questions; we invited interviewees to be candid in their responses and affirmed our commitment to preserving confidentiality and anonymity of both themselves and their universities in accordance with our ethical approval conditions.

We debriefed each interview experience with one another, sharing our reactions and reflections. We incorporated changes from participant validations of the transcripts in the final transcripts, and de-identified them, before beginning analysis. Our final data set comprised the final anonymized versions of 15 interview transcripts uploaded to an NVivo project for collaborative coding.

\section{Analysis}

The themes that emerged from the literature review and our experiences-access, change, culture, innovation, strategy, leadership-informed and defined the initial descriptive codes we considered for exploring the interview transcripts. We coded the topics covered in each transcript collaboratively and synchronously, using the screen sharing feature of our university-supported Skype for Business application to discuss and negotiate the analyses of these data. We co-coded all transcripts together, staying close to our data, and capturing participants' voices. (Morse et al., 2002; Syed \& Nelson, 2015). Within the first few coding sessions, we had a complete list of defined codes, grounded in the literature and our data, that covered all topics.

\section{Findings}

We assigned descriptive codes to passages within the transcripts (see Table 1 for definitions of the 12 codes we consider in this report).

As expected, given our research questions and the nature of our topic, we assigned the code Change most often. Other frequently used codes were Strategy, Structure, Leadership, Learning and Teaching, Culture, Technology, and Access. We assigned the code Recommendations when participants made suggestions for lessons learned or advice offered. Less frequently used codes, including Revenue and Budget and Resistance, generated comments from most participants; often they emerged along with other issues and described challenges, frustrations or difficulties.

Our coding process led us to a general recognition of our participants' perspectives which we sorted into five preliminary themes related to research questions about the drivers and impacts of changes experienced. Each is discussed below and illustrated with quotations from participants.

\section{Access and Revenue are Drivers of Online Learning}

Participants all commented on drivers leading to increased support of online learning initiatives over the fifteen years. They described perceptions of increasing accessibility of their offerings to new groups of students (University A), whether from non-traditional backgrounds (University C), previously un- or underserved geographical areas (University $E$ and $F$ ) or attracting those with various learning challenges (University B). Participant $Y$ indicated that the "whole [online] program now is part of the university's commitment to accessible education." Others commented on the importance of anticipated and actual revenue increases to attracting buy-in from university leaders. At a time of reduced funding for post-secondary education in many provinces, new sources of revenue and increases in enrolment were welcome. Participant $O$ indicated a move into international markets was facilitated by online offerings, and Participant P stated: "When we talk about institutional leadership and support, it is very easy for me to get the buy-in from Finance when I show growth numbers." 
Table 1

Definitions of Codes Used in this Report

\begin{tabular}{ll}
\hline Code & Definition \\
\hline Change & $\begin{array}{l}\text { disruption in practice, process, policy, or vision; included stories that revolutionize, } \\
\text { innovate, or disintegrate } \\
\text { Strategy }\end{array}$ \\
Structure & $\begin{array}{l}\text { lines of authority describing assignment of roles, power, and responsibilities } \\
\text { qualities, attributes, or practices of individuals with responsibilities, whether as- } \\
\text { seadership }\end{array}$ \\
signed or not \\
engaging with learners to enable understanding and mastery of knowledge; includ- \\
ed instructional design processes \\
underlying beliefs, assumptions, values, and ways of interacting that contribute to \\
the unique social and psychological organizational environment \\
hardware and software tools used in communication, learning, and/ or teaching \\
Technology \\
Innovation
\end{tabular}

\section{Organizational Structures and Roles are Changing}

All seven universities experienced changing organizational structures. Four of the seven (Universities C, E, F, and $G$ ) saw centralization of the structure of management and delivery for online learning. Initially in these institutions online learning was housed in and supported by separate Continuing Education units that managed distance education programs. Over time, centrally supported centres for teaching and learning assumed responsibility for the design and development of online and technology-enhanced courses and programs, and, in some cases, elements of the technology infrastructure as well. By 2017, online learning technologies and support services were available beyond distance and continuing education programs to most faculty and programs across most campuses. Participants described the transition process as challenging for staff, sometimes lacking in vision or strategy, and still in progress in some cases:

When the decision was made to move...then the distance and online staff moved over to the Centre for Teaching and Learning. Well actually, they didn't even move together. They moved the development staff first and then a year later the delivery staff. (Participant U)

Participants from the other three universities $(A, B$, and $D$ ) also reported organizational changes to structure and roles supporting the technology infrastructure and the course development process. One university moved from a centralized to a distributed model in an attempt to secure faculty support for online course design and development. Participant $L$ described the result: 
From a Faculty perspective, I think we've streamlined in terms of our current structure, we have an online course development and production system where any faculty can just step in any time and see what the status of their course is, what the information is.

Another university (D) struggled with pronounced dissent among groups of faculty and staff devoted to one modality of teaching and learning over another once online education was added to traditional offerings. And most participants described challenges related to supporting the LMS effectively, resulting in new roles or reporting relationships. Participant $\mathrm{Q}$ described one significant change:

I finally worked out a partnership with IT, where we kind of decided on how to split our responsibilities, in terms of supporting our students, and the LMS, where they would fall to IT and where they would fall to us. Negotiated to um, take-not take over, that's the wrong word-but to um, assume all the online support for on-campus students as well as our students. That was a big change.

All interviewees described the increasing importance of the role of instructional designers in relation to the expansion of online course and program design. They described changes in management structure to embed this role as a resource to all faculty members learning to teach online. For example, Participant $P$ described "One of the things that was developed here, well past due, but it had a rough start, was a Centre for Learning and Teaching dedicated to campus-based faculty." At University G, the instructional designers were all transferred to a new non-academic Centre for Teaching and Learning. Participant Q stated "You do need a centre of expertise, I think, that can support all of the schools. So ideally that would be integrated within the overall, a centre for teaching and learning that is built to support all modalities." Participant $U$ portrayed a university that over time expanded the centralized model to create a shared, distributed structure for supporting online course development: "We started to put instructional designers in Faculties that had a lot of online courses. So they were our staff but they would spend, some time being in the Faculty as a resource to that Faculty."

\section{Traditional Learning and Teaching Practices are Changing}

Emerging from this recognition of the essential role of the instructional designer was the perspective that online learning and teaching approaches challenge traditional cultures and practices, whether by distance or in person. Participants offered comments about positive impacts, describing additional specialized resources for supporting classroom-based technology-facilitated teaching. They stated that the enhanced focus on designing courses for effective learning was resulting in improvements to the quality of classroom teaching.

An appreciation developed for the expertise and influence of staff and faculty experienced in distance education design and development methods and online pedagogies. One participant reported that this guidance was valued:

But I think now, especially now with these workshops we're putting on, we were trying to draw in on-campus faculty and share ideas in order to think creatively actually about how to teach online. And how to understand it better. I know in my experience I've had quite a few faculty members say "I wish l'd known about this way of developing courses for my own self; can I use this." (Participant S)

Another participant described the power of the conversations that were emerging and their impacts on traditional approaches to course design:

I think one thing that it has influenced in some way is the conversation around course development, and what does good course development look like...that's helping to bridge some conversations around face-toface courses. But that idea around the intensity and the purposefulness of creating an online course-why shouldn't you be applying those same principles to every course that you teach? (Participant V)

\section{Challenges Experienced Were Multi- Dimensional}

The challenges experienced during the adoption of online learning included a lack of dedicated resources and more generalized resistance to change. Participants 
were sometimes emphatic about staffing deficiencies and the shortage of other resources for the move to online learning. Participant $\mathrm{Q}$ proposed a solution to the difficulties faced in one university: "A centralized support group that's competent to support faculty, assist with program development, to come alongside faculty in putting courses online, and able to actually fund online course development. I think that's a key piece." Participant $\mathrm{R}$ commented that after years of struggle for resources during the transition, "the university didn't actually invest in the staff up until now." And Participant $P$ was candid about the challenges faced: "When distance education is being introduced into the institution, or any initiative for that matter, unless people understand it and believe in it, and are willing to put resources towards it, it's going to be a very tough slog."

Resistance to change comes in many forms. Some participants linked aspects of the resistance to the lack of adequate resources for supporting the adoption of online learning pedagogies and technologies. Others expressed the resistance in cultural terms. Participant $\mathrm{K}$ indicated that

there was just some inherent resistance built into our DNA, and so I recall really, you know, significant and entrenched conversations and positions around students want a "course in a box" right, so just that resistance to moving some of the learning materials into a learning management system, was just such an enormous change.

In some cases, participants expressed hope for declining resistance over time. Participant $\mathrm{R}$ said "The resistance is still there and that won't change until the persons themselves, their perceptions change.... It's when they hear the experiences of other faculty members, the positive experiences, then it's changing those perceptions." In other cases, participants conveyed a sense of resentment about personal impacts of change, dissatisfaction with the process of moving to online learning, and frustration with the lack of vision and strategic leadership.

\section{Leadership is Critically Important}

The importance of articulating a vision and strategy for the future was mentioned by all participants during the course of their interviews. A lack of supportive executive leadership dominated the stories, even from those at the senior level. Vision and buy-in were mentioned frequently as essential characteristics for successful management of change. Championship from senior leaders was expected, as was a clear articulation of the reasons for moving online (Participants $\mathrm{P}, \mathrm{M}, \mathrm{O}, \mathrm{X}$ ). Participant $T$ concluded that establishing "a common vision of what online learning is for institutions is very, very important" and that "lesson number one is that it will go a whole lot easier when there is that championship at...the top... very senior championship."

Sharing the vision with everyone in the organization can contribute to successful adoption of online learning in two ways-recognizing and enabling others throughout the organization, and managing the resistors. Participant $P$ asked "can you have a leader without vision? I don't think you can have a good leader without vision," emphasizing the importance of "managing the naysayers, but more importantly, encouraging the champions that share the vision." Participant Q pointed out that, in line with the role of universities in society, "we need expanded visions of online learning and then beyond, stretching it to access and then the ideas of social justice and the role that universities can play in society, beyond corporatization," suggesting that faculty and staff would embrace new mandates of this sort. He elaborated:

I think online learning if it's done particularly with the motivation of being inclusive both internally within the university, not just with a certain group, but something that's owned by the whole university as part of a larger vision of the needs of society and the pre-eminence of communication technologies, then it's critical to engage with the idea that it's going to affect every part of the university and every part needs to be consulted. (Participant Q)

Most participants recommended that consultation and engagement of faculty and staff would help address resistance and confusion. Participant $\mathrm{M}$ concluded:

I think you end up at involving people in the process.... I think that consultation and engagement is probably the key. Of course the challenge is you can never do enough of it. But the more the better in some way.

Participant $Y$ focused on the need for leaders to ensure participation and contribution from all: "students, 
librarians, centre for teaching and learning, the technology, faculty, instructional support, deans, whoever. Get everybody involved. Because everybody, it transforms the institution from end to end, if you are doing it right. It touches every part of the institution." Buy-in needs to be encouraged and facilitated by leaders with vision and communication skills who espouse a strategy for innovation, because online

is not for the faint of heart. It's more expensive. It's more resource intensive. It's all those things. So, you have to have somebody that has vision and I'm going to say kind of all the way up. It has to start at the top... to say...this is something we're committed to. (Participant $\mathrm{T}$ )

\section{Discussion}

We undertook a multi-institutional approach in our study by exploring the 15-year transition to online learning in seven Canadian distance universities. Sixteen participants described their experiences as leaders and facilitators of change. While each story was unique, we focus in this article on the similarities. Administrators and information technology specialists grappled with the selection, introduction, and support of learning management systems and other technologies that effectively facilitated learning. At the same time, instructional designers in partnership with faculty collaborated to design courses and programs using technologies appropriate for online delivery. They built on expertise in systematic distance education design and development, purposefully focused on learners and learning, and over time they extended those skills into face-to-face, on-campus learning environments. Various academic and administrative models emerged, depending on institutional context and culture. We acknowledge the common issues encountered, the challenges faced and the disruptive impacts on individuals, structures, and practices.

Research has explored aspects of online learning in higher education (Fredericksen, 2017; Scoppio \& Covell, 2016), but few studies have looked at broad organizational change and challenges associated with the move to online learning (Marshall, 2010a). Our study may be unique in that it explores the perspectives of Canadian distance educators about their move to online learning. It addresses a gap in the literature by providing insight into challenges and the learning that occurred in participating universities during a disruptive transition. Our research contributes to the history of organizational change and the evolution of online learning in Canadian universities. Our reading of the literature suggests perspectives related to the adoption of online education are similar across various geographical contexts. Thus while we describe Canadian experiences, our study may be of interest in other countries as well. We invite readers to determine the applicability of our findings, conclusions and recommendations to their own contexts.

\section{Conclusions and Recommendations}

This study has begun to answer our research questions. We learned that the move from traditional distance education to online distance education was driven by commitments to access and revenue generation, necessitated by declining government grants, and expedited by advances in technology. Over time, the skills of distance educators were instrumental in on-campus adoption of online learning. We identified disruptions in academic and professional practices, roles, and structures. We confirmed that while the articulation of a long-term vision for the appropriate place of online learning was seen as a critical role for executive leadership, it was perceived as lacking. We understood that the resources and other supports needed to enable the adoption of new technologies and pedagogies were not available in these universities in the early 2000s. We learned, however, that solutions were cobbled together.

Our findings indicate that leadership for the move to online learning emerged from the dynamic interactions of individuals within their universities. Instructional designers, information technology professionals, managers, and faculty members who were champions of online learning were change agents, bringing their expertise and enthusiasm into the conversations, and playing an essential role in facilitating the move. Their collaborations helped increase awareness of effective technology-enabled learning and teaching in both fully online and campus-based environments. Effective leadership, we conclude, exists in recognizing and supporting the expertise of all these groups.

While traditional models of teaching and learning have endured, the continued growth of online learning is inevitable given advances in technology and the increasing demand for access to life-long learning. When 
considering a move to online learning, it is important to ask questions about goals, expected outcomes, and necessary resources before decisions are made. The answers to these questions require consultation and engagement. Leaders at all levels must faciltate the conditions for change by enabling conversations throughout the institution about the value of online teaching and learning. Those with knowledge, skills, and competencies in distance education and experience in online learning are essential to effective implementation. Professional development initiatives are critical and must include support for the understanding and application of distance education pedagogies and technologies.

We see a need for similar research in various learning environments and more recent timeframes. For example, replicating our study could provide evidence to inform the implementation of technology-supported learning in classrooms. As well, future studies that explore the perspectives of students and faculty could ensure the needs of learners and teachers are considered as education moves online. There is also a need for further exploratory research on the leadership and management processes required to support disruptive academic change in universities.

\section{Acknowledgements}

The authors acknowledge the willing participation of interviewees. We recognize funding from Athabasca University. And we appreciate the work of our research assistant, Kathryn Johnson.

\section{References}

Advisory Committee for Online Learning (Ed.). (2001). The e-learning e-volution in colleges and universities: A pan-Canadian challenge. Government of Canada.

Anderson, T. (2008). The theory and practice of online learning. Athabasca University Press. https://www. aupress.ca/books/120146-the-theory-and-practiceof-online-learning/

Bass, B., \& Riggio, R. (2006). Transformational leadership (2nd ed.). Lawrence Erlbaum Associates, Inc.

Bates, T., \& Sangrà, A. (2011). Managing technology in higher education: Strategies for transforming teaching and learning. Jossey-Bass. https://www. batesandsangra.cal

Beaudoin, M. (2016). A primer for higher education decision makers. New Directions for Higher Education, 173, 9-19. https://doi.org/10.1002/he.20175

Boyce, M. E. (2003). Organizational learning is essential to achieving and sustaining change in higher education. Innovative Higher Education, 28(2), 119-136. https://doi.org/10.1023/ B:IHIE.0000006287.69207.00

Brown, S. (2013). Large-scale innovation and change in UK higher education. Research in Learning Technology, 21, 1-13. https://doi.org/10.3402/rlt. v21i2.22316

Cameron, D. M. (2002). The challenge of change: Canadian universities in the 21st century. Canadian Public Administration, 45(2), 145-174. https://doi. org/10.1111/j.1754-7121.2002.tb01078.x

Canadian Council on Learning. (2009). The state of e-learning in Canada. ERIC Clearinghouse.

Caruth, G. D., \& Caruth, D. L. (2013). Understanding resistance to change: A challenge for universities. Turkish Online Journal of Distance Education (TOJDE), 14(2), 12-21. https://dergipark.org.tr/en/pub/ tojde/issue/16896/176041

Charpentier, M., Lafrance, C., \& Paquette, G. (2006). International e-learning strategies: Key findings relevant to the Canadian context. Canadian Council on Learning.

Chen, B. (2009). Barriers to adoption of technology-mediated distance education in higher-education institutions. Quarterly Review of Distance Education, 10(4), 333-338. https://eric.ed.gov/?id=EJ889336

Council of Ministers of Education. (2001). CMEC vision statement on on-line learning in postsecondary education.

Daniel, J. S. (1999). The mega-universities and knowledge media: Technology strategies for higher education (2nd ed.). Kogan Page.

Denzin, N. K., \& Lincoln, Y. (Eds.). (2018). The Sage handbook of qualitative research (5th ed.). SAGE Publications, Inc. 
Donovan, T., \& Bates, T. (2018). 2018 Canadian survey of online and digital learning. http://www.cdlra-acrfl. ca/publications/

EDUCAUSE. (2020). 2020 EDUCAUSE horizon report:Teaching and learning edition. https://library.educause.edu/resources/2020/3/2020-educause-horizon-report-teaching-and-learning-edition

Fredericksen, E. E. (2017). A national study of online learning leaders in US higher education. Online Learning, 21(2). https://doi.org/10.24059/olj. v21i2.1164

Gioia, D. A., \& Thomas, J. B. (1996). Identity, image, and issue interpretation: Sensemaking during strategic change in academia. Administrative Science Quarterly, 41(3), 370-403. https://doi. org $/ 10.2307 / 2393936$

Graetz, F., \& Smith, A. C. T. (2010). Managing organizational change: A philosophies of change approach. Journal of Change Management, 10(2), 135-154. https://doi.org/10.1080/14697011003795602

Gronn, P. (2000). Distributed properties: A new architecture for leadership. Educational Management \& Administration, 28(3), 317-338. https://doi. org/10.1177/0263211X000283006

Guri-Rosenblit, S. (2014). Distance education systems and institutions in the online era: An identity crisis. In O. Zawacki-Richter \& T. Anderson (Eds.), Online distance education: Towards a research agenda ( $\mathrm{pp}$. 109-130). Athabasca University Press. https://www. aupress.ca/books/120233-online-distance-education/

Holmberg, B. (1994). Theory and practice of distance education (2nd ed.). Routledge. https://www.routledge.com/Theory-and-Practice-of-Distance-Education-2nd-Edition/Holmberg/p/book/9780415112925

Hughes, J., \& Mighty, J. (2010). Taking stock: Research on teaching and learning in higher education. McGill-Queen's University Press.

Ives, C. (2002). Designing and developing an educational systems design model for technology integration in universities [Doctoral dissertation, Concordia University]. Spectrum Research Repository at Concordia University.
Johnson, N. (2019). Publications-2019. Canadian Digital Learning Research Association. https://onlinelearningsurveycanada.ca/publications-2019/

Keegan, D. (1993). Theoretical principles of distance education (1st ed.). Routledge. https://www.routledge. com/Theoretical-Principles-of-Distance-Education-1st-Edition/Keegan/p/book/9780415089425

Kezar, A. (2013). Understanding sensemaking/sensegiving in transformational change processes from the bottom up. Higher Education, 65(6), 761-780. https://doi.org/10.1007/s10734-012-9575-7

Kezar, A., \& Eckel, P. D. (2002). The effect of institutional culture on change strategies in higher education: Universal principles or culturally responsive concepts? The Journal of Higher Education, 73(4), 435-460. https://doi.org/10.1080/00221546.2002.1 1777159

King, E., \& Boyatt, R. (2015). Exploring factors that influence adoption of e-learning within higher education. British Journal of Educational Technology, 46(6), 1272-1280. https://doi.org/10.1111/bjet.12195

Laurillard, D. (2002). Rethinking university teaching: A conversational framework for the effective use of learning technologies. RoutledgeFalmer.

Lichtenstein, B., Uhl-Bien, M., Marion, R., Seers, A., Orton, J., \& Schreiber, C. (2006). Complexity leadership theory: An interactive perspective on leading in complex adaptive systems. Emergence: Complexity and Organization, 8(4), 2-12. https://link.gale.com/ apps/doc/A159180383/AONE?u=atha49011\&sid=AONE\&xid=44404252

Maher, C., Hadfield, M., Hutchings, M., \& de Eyto, A. (2018). Ensuring rigor in qualitative data analysis: A design research approach to coding combining NVivo with traditional material methods. International Journal of Qualitative Methods, 17(1). https://doi. org/10.1177/1609406918786362

Marshall, S. (2010a). Change, technology and higher education: Are universities capable of organisational change? ALT-J, Research in Learning Technology, 18(3), 179-192. https://doi.org/10.14742/ajet.1018

Marshall, S. (2010b). A quality framework for continuous improvement of e-learning: The e-learning matu- 
rity model. Journal of Distance Education, 24(1), 143-165. https://doi.org/10.14742/ajet.1018

Morse, J., Barrett, M., Mayan, M., Olson, K., \& Spiers, J. (2002). Verification strategies for establishing reliability and validity in qualitative research. International Journal of Qualitative Methods, 1(2), 13-22. https://doi.org/10.1177/160940690200100202

Norris, D., Brodnick, R., Lefrere, P., Gilmour, J., \& Baer, L. (2013). Transforming in an age of disruptive change: Part 1: Back to the future, zooming to the present. Planning for Higher Education, 41(2), 18-32. https://link.gale.com/apps/doc/A342177540/ PPVC?u=atha49011\&sid=PPVC\&xid=7fc42bb5

Nworie, J. (2006). Academic technology in higher education: Organizing for better results. Journal of Educational Technology Systems, 35(1), 105-128. https://doi.org/10.2190/D573-8274-660N-4032

Organisation for Economic Co-operation and Development. (2019). Skills matter: Additional results from the survey of adult skills. https://www.oecd-ilibrary. org/education/skills-matter 1f029d8f-en

Palaganas, E., Sanchez, M., Molintas, M. V., \& Caricativo, R. (2017). Reflexivity in qualitative research: $A$ journey of learning. The Qualitative Report, 22(2), 426-438. https://nsuworks.nova.edu/tqr/vol22/iss2/5

Palvia, S., Aeron, P., Gupta, P., Mahapatra, D., Parida, R., Rosner, R., \& Sindhi, S. (2018). Online education: Worldwide status, challenges, trends, and implications. Journal of Global Information Technology Management, 21(4), 233-241. https://doi.org/10 $.1080 / 1097198 X .2018 .1542262$

Paul, R. (2014). Organization and management of online and distance learning. In O. Zawacki-Richter \& T. Anderson (Eds.), Online distance education: Towards a research agenda (pp. 175-196). Athabasca University Press. https://www.aupress.cal books/120233-online-distance-education/

Paul, R. (2015). Leadership under fire (2nd ed.). McGill-Queen's University Press. https://www.mqup. ca/leadership-under-fire--second-edition-products-9780773545311.php

Peters, O. (2002). Distance education in transition: New trends and challenges. Bibliotheks- und Informa- tionssystem der Universität Oldenburg.

Qayyum, A., \& Zawacki-Richter, O. (2018). Open and distance education in a digital age. In A. Qayyum \& 0. Zawacki-Richter (Eds.), Open and distance education in Australia, Europe and the Americas: National perspectives in a digital age (pp. 1-8). Springer. https://doi.org/10.1007/978-981-13-0298$\underline{51}$

Russell, C. (2009). A systemic framework for managing e-learning adoption in campus universities: Individual strategies in context. ALT-J: Research in Learning Technology, 17(1), 3-19. https://doi. org/10.1080/09687760802649871

Salmon, G., \& Angood, R. (2013). Sleeping with the enemy. British Journal of Educational Technology, 44(6), 916-925. https://doi.org/10.1111/bjet.12097

Scoppio, G., \& Covell, L. (2016). View of mapping trends in pedagogical approaches and learning technologies: Perspectives from the Canadian, international, and military education contexts. Canadian Journal of Higher Education, 46(2), 127-147. https://doi. org/10.47678/cjhe.v46i2.186043

Simonson, M., Smaldino, S., Albright, M., \& Zvacek, S. (2012). Teaching and learning at a distance: Foundations of distance education (5th ed.). Pearson Education.

Statistics Canada. (2020). Canadian postsecondary enrolments and graduates, 2017/2018. The Daily. https://www150.statcan.gc.ca/n1/daily-quotidien/200219/dq200219b-eng.htm

Syed, M., \& Nelson, S. C. (2015). Guidelines for establishing reliability when coding narrative data. Emerging Adulthood, 3(6), 375-387. https://0-doi-org.aupac.lib.athabascau. ca/10.1177/2167696815587648

Uhl-Bien, M., \& Arena, M. (2018). Leadership for organizational adaptability: A theoretical synthesis and integrative framework. The Leadership Quarterly, 29(1), 89-104. https://doi.org/10.1016/j. leaqua.2017.12.009

Uhl-Bien, M., Marion, R., \& McKelvey, B. (2007). Complexity leadership theory: Shifting leadership from the industrial age to the knowledge era. The 
Leadership Quarterly, 18(4), 298-318. https://doi. org/10.1016/j.leaqua.2007.04.002

United Nations Educational, Scientific and Cultural Organization. (2018). UNESCO Institute for Statistics (UIS). Education stats database. http://data.uis. unesco.org

Weick, K. E., Sutcliffe, K. M., \& Obstfeld, D. (2005). Organizing and the process of sensemaking. Organization Science, 16(4). https://doi.org/10.1287/ orsc. 1050.0133

Weller, M. (2020). 25 years of ed tech. Athabasca University Press. https://doi.org/10.15215/aupress/9781771993050.01

\section{Contact Information}

Dr. Cindy Ives

cindyi@athabascau.ca 